\title{
Investigating the Possibility to Reduce the Residual Stress Level in 2.5D Cutting Using Titanium Coated Carbide Ball End Mill
}

\author{
N. Masmiati, ${ }^{1,2}$ H. S. Chan, ${ }^{1}$ Ahmed A. D. Sarhan, ${ }^{1,3}$ M. A. Hassan, ${ }^{1,3}$ and M. Hamdi ${ }^{1}$ \\ ${ }^{1}$ Centre of Advanced Manufacturing and Material Processing, Department of Mechanical Engineering, \\ University of Malaya, 50603 Kuala Lumpur, Malaysia \\ ${ }^{2}$ Institute of Product Design and Manufacturing, Universiti Kuala Lumpur, Cheras, 56100 Kuala Lumpur, Malaysia \\ ${ }^{3}$ Department of Mechanical Engineering, Faculty of Engineering, Assiut University, Assiut 71516, Egypt
}

Correspondence should be addressed to Ahmed A. D. Sarhan; ah_sarhan@um.edu.my

Received 2 April 2014; Accepted 6 August 2014; Published 27 August 2014

Academic Editor: Haiming Lu

Copyright @ 2014 N. Masmiati et al. This is an open access article distributed under the Creative Commons Attribution License, which permits unrestricted use, distribution, and reproduction in any medium, provided the original work is properly cited.

End milling is a multipoint cutting process in which material is removed from a workpiece by a rotating tool. It is widely used in cutting $2.5 \mathrm{D}$ profiles such as point-to-point, contouring, and pocketing operations. 2.5D machining possesses the capability to translate in all 3 axes but can perform the cutting operation in only 2 of the 3 axes at a time. This study focuses on optimizing the cutting parameters, such as machined surface inclinationangle, axial depth of cut, spindle speed, and feed rate for better surface integrity, namely, microhardness, residual stress, and microstructure in $2.5 \mathrm{D}$ cutting utilizing a titanium-coated carbide ball end mill. An optimization method known as Taguchi optimization, which includes planning, conducting, and analyzing results of matrix experiments, was used in order to achieve the best cutting parameter level. Data analysis was conducted using signal-to-noise $(S / N)$ and target performance measurement (TPM) response analysis and analysis of variance (Pareto ANOVA). The optimum condition results obtained through analysis show improvements in microhardness of about $0.7 \%$, residual stress in the feed direction of about $18.6 \%$, and residual stress in the cutting direction of about $15.4 \%$.

\section{Introduction}

Milling is a machining process of removing material by the relative motion between a workpiece and rotating cutter with multiple cutting edges. It is an interrupted cutting operation in which the teeth of the milling cutter enter and exit the workpiece during each revolution. With $2.5 \mathrm{D}$ cutting in milling it is possible to perform point-to-point, contouring, and pocketing operations [1]. 2.5D is similar to $3 \mathrm{D}$ machining in the fact that it can translate in all 3 axes but has a limitation of only being able to perform in 2 of the 3 axes at a time or on the same plane that coincides with one of the milling machine planes. The code for $2.5 \mathrm{D}$ machining is normally less than for 3D machining and the tool path is generally simple and quick. 2.5D operation normally involves two types of operation: roughing and finishing processes. During operation, the depth of cut remains constant and the cutter movement only interpolates 2 axes simultaneously, meaning that the cutter moves only on the main planes $X Y, Y Z$, and
$Z X$ and then moves to the next depth and repeats the same movement. A terrace-like approximation of the required shape is produced in the roughing process in order to remove excess material. Once roughing is done, finishing is used to transform the part into its final design shape with acceptable tolerance [2]. Previously, research has been done on 2.5D cutting, regarding, for instance, the efficiency of the cutting path in $2.5 \mathrm{D}$ cutting of pocket milling $[3,4]$, developing a generic algorithm for a cutter engagement function in $2.5 \mathrm{D}$ milling [5], cutting tool sizes for a $2.5 \mathrm{D}$ pocket [6], and so forth. However, there is still lack of research on product surface integrity after being machined in $2.5 \mathrm{D}$ cutting.

The term "surface integrity" was coined by Michael Field and John F. Kahles in 1964. There are two aspects to surface integrity: topography characteristics and surface layer characteristics. Topography comprises surface roughness, waviness, errors of form, and flaws. The surface layer characteristics can change through manufacturing, whereby the surface layer sustains local plastic deformation, residual 
stresses, cracks, and hardness. The surface integrity after machining processes correlates very closely with the cutting parameters $[7,8]$ and tool geometries [9]. Improper parameter selection for the machining process will damage the surface integrity of a product. Therefore, it is important to understand the relationship between the cutting conditions and surface integrity of the machined part, such as the microhardness and residual stress of the machined surface due to the effects on product appearance, performance, and reliability.

The surface layers' characteristics beneath the machined surface change through the manufacturing process, with the surface layer sustaining local plastic deformation, residual stresses, cracks, and hardness. The existence of a softening region beneath the surface also influences the microhardness of a machined surface [10]. Dominant mechanical loading could cause work hardening on the machined surface, thus, increasing the microhardness [11]. The depth of this workhardened layer varies depending on the type of mechanical and thermal interaction. Moreover, Sun and Guo [12] reported that surface materials experienced significant strain hardening in the range of $68-80 \%$ induced by surface deformation.

Residual stresses in a body are those which are not necessary for maintaining equilibrium between the body and its environment [13]. They originate from misfits between different regions; these misfits sometimes span large distances and may be caused, for instance, by the nonuniform plastic deformation of a bent bar or by sharp thermal gradients during welding or heat treatment. Hence, residual stresses can be formed by thermal deformation, mechanical deformation, or combined thermal and plastic deformation [14]. The residual stresses in machined components can be tensile or compressive stresses. The mechanical loading (e.g., cutting force) generally introduces compressive stresses due to contact pressure, whereas thermal loading is generally associated with tensile stresses [15]. If the specimen surface is in a state of compression, such as that produced from shot peening, carburizing, or burnishing, it is more difficult to initiate a fatigue crack and so the lifetime is extended. Conversely, processes that produce residual surface tension, such as welding or machining, can significantly reduce the fatigue lifetime of a product. In machining, residual stresses are closely related to the cutting parameters used during machining. Higher depth of cut and feed rate exhibited detrimental effects by generating higher stresses [16]. Increasing cutting speed and feed per tooth causes compressive stress to decrease, probably due to a higher thermal effect on the workpiece surface [17]. Sun and Guo [12] reported that the dominant mechanical deformation at all cutting speeds tends to produce compressive residual stress. Machining can also lead to microstructural transformations due to high temperature and it may cause tensile or compressive stresses depending on the material used and machining conditions [18].

Ezugwu et al. [19] observed that typical machined surfaces are generated when machining Ti-6Al-4V alloy with polycrystalline diamond (PCD) tools under conventional and high pressure coolant supplies. It was found that well-defined

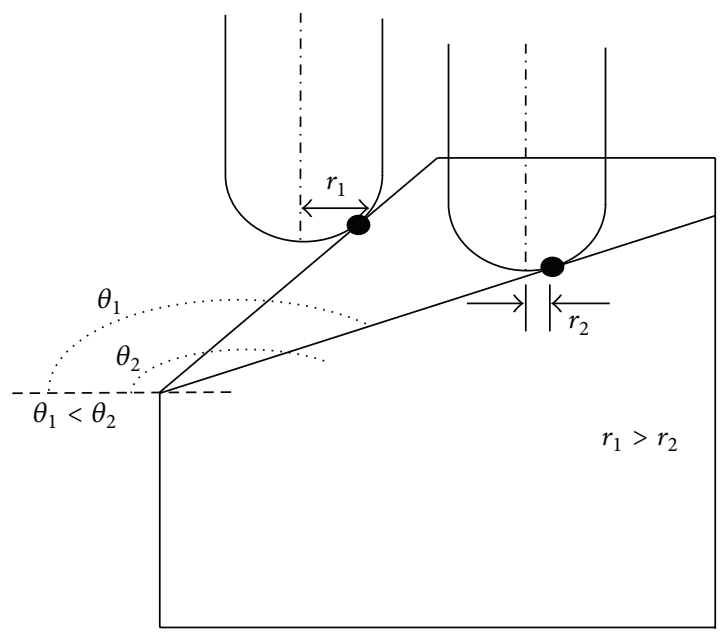

FIGURE 1: Schematic of the tool position during machining.

uniform feed marks are generated on the surfaces running perpendicular to the tool feed direction. Feed marks area natural defect due to feeding. Besides, micropits are also found on the surfaces due to brittle fractures of hard carbide inclusion within the immediate surface during the shearing of the workpiece material by the tool. Furthermore, surface tearing can be randomly observed on machined samples [20]. Tearing of machined surfaces is likely to occur on account of the cutting tool part (the small part that peels off from its origin to form tool wear) and built-up edge (BUE) deposited on the machined surface.

In line with the literature above, to optimize the cutting parameters for better surface integrity in $2.5 \mathrm{D}$ cutting, this study was conducted by anticipating spindle speed, feed rate, depth of cut, and machined surface inclination angle as control variables. In $2.5 \mathrm{D}$ cutting, the effects of these parameters need to be investigated, especially the way the inclined machined surface angle affects the cutting speed (Figure 1). Increasing the machined surface inclination angle, $\theta$, will cause the distance, $r$, to decrease. Furthermore, decreasing $r$ will decrease the cutting speed since the tool diameter is directly proportional to the cutting speed leading to different surface integrity characteristics.

The main objective of this research work is to find the best combination of parameters in milling carbon steel workpieces utilizing a titanium-coated carbide ball end mill to obtain higher surface hardness and lower residual stress. The conventional method to achieve this is the "trial and error" approach. However, due to the large number of experiments, the "trial and error" approach is very time consuming. Hence, a reliable systematic approach for optimizing the machining parameters is required.

\section{Experimental Design}

2.1. The Optimization Method and Identifying the Orthogonal Array. Experiments are carried out by researchers in all fields of study to compare the effects of several conditions or to discover something new. Statistical experimental design is 
TABLE 1: Factors and levels used in the experiments.

\begin{tabular}{lccc}
\hline \multirow{2}{*}{ Factors } & \multicolumn{3}{c}{ Experimental condition levels } \\
& 1 & 2 & 3 \\
\hline $\begin{array}{l}\text { (A) Machined surface inclination } \\
\text { angle }\left(\theta^{\circ}\right)\end{array}$ & 100 & 110 & 120 \\
$(B)$ Axial depth of cut $(\mathrm{mm})$ & 0.1 & 0.25 & 0.5 \\
$(C)$ Spindle speed $\left(\mathrm{min}^{-1}\right)$ & 3200 & 3700 & 4200 \\
$(D)$ Feed rate $(\mathrm{mm} / \mathrm{min})$ & 870 & 920 & 970 \\
\hline
\end{tabular}

a process of planning experiments so that appropriate data will be collected, the numbers of experiments to acquire necessary information are reduced, and the collected data will be analyzed using suitable statistical methods. The Taguchi optimization method developed by Professor Dr. Genichi Taguchi in the early 1980s is used in this study. It is an optimization method that includes planning, conducting, and analyzing the results of matrix experiments in order to achieve the best control factor levels [21]. The design of experiment is based on orthogonal arrays (OAs) which minimize the size of the experiments with optimum settings of control parameters. It is a fractional factorial matrix which assures a balanced comparison of levels of any factor or interaction of factors. OA is a matrix of numbers arranged in rows and columns, where each row represents the level of factors in each run and each column represents a specific factor that can be changed from each run. Taguchi's method of experimentation is meant to identify the main factors that cause the greatest variation and to determine control parameters with the least variability. The best control factor levels are those that maximize the signal-to-noise ratios $(S / N)$, which are log functions of desired output, serve as objective functions for optimization, and help with data analysis and optimum result prediction. Extensive research has been done on optimization methods, especially the Taguchi method, and it has been proven that with a minimum number of experiments process performance can be improved [22, 23].

The standardized orthogonal array L9 $\left(3^{4}\right)$ consisting of nine experiments with four different factors and three different experimental condition levels has been chosen. The factors and levels are specified in Table 1. The levels of machined surface inclination angle, Factor $A$, and the axial depth of cut, Factor $B$, were selected based on the results in the preliminary experiment, while levels for both spindle speed, Factor $C$, and feed rate, Factor $D$, were selected based on the tool manufacturer's recommendation. The nine experiments with details of combinations for all control factors $(A-D)$ are shown in Table 2.

2.2. Experimental Setup and Procedure. After designing the experiment using the orthogonal array, the next step is to conduct the experiment based on the OA. Figure 2 shows the experimental setup used in this research. A five-axis CNC machining center (SPINNER U-620) built with a Siemens controller was used. The tilting table integrated in the machine structure is useful for workpieces of about 500 $\times 500 \times 500 \mathrm{~mm}$. The machine is designed for the highest
TABLE 2: L9 $\left(3^{4}\right)$ orthogonal array.

\begin{tabular}{lcccc}
\hline \multirow{2}{*}{ Experiment number } & \multicolumn{4}{c}{ Control factors and levels } \\
& $A$ & $B$ & $C$ & $D$ \\
\hline 1 & 1 & 1 & 1 & 1 \\
2 & 1 & 2 & 2 & 2 \\
3 & 1 & 3 & 3 & 3 \\
4 & 2 & 1 & 2 & 3 \\
5 & 2 & 2 & 3 & 1 \\
6 & 2 & 3 & 1 & 2 \\
7 & 3 & 1 & 3 & 2 \\
8 & 3 & 2 & 1 & 3 \\
9 & 3 & 3 & 2 & 1 \\
\hline
\end{tabular}

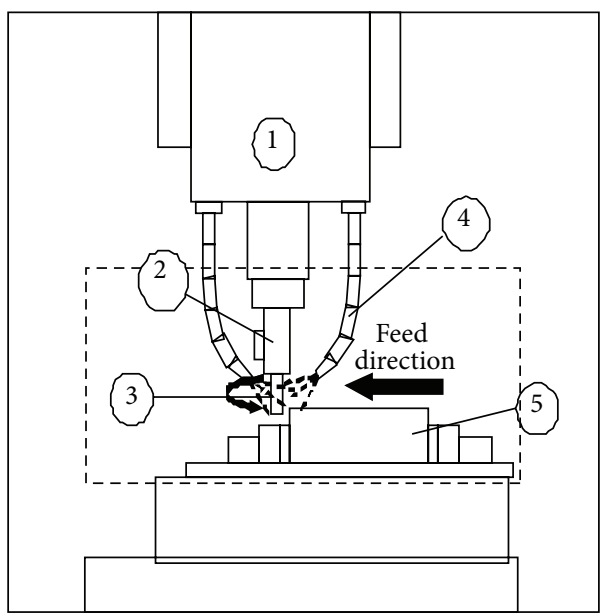
(1) CNC milling center
(2) Tool holder
(4) Coolant supply
(3) Cutting tool
(5) Carbon steel workpiece

FIGURE 2: Schematic diagram of the experimental setup.

precision, best access to the working area and top-value technical data as standard, such as maximum spindle speed of $12000 \mathrm{~min}^{-1}$, 32 tool changes, $11 / 29 \mathrm{~kW}$ spindle power (S6 $40 \%$ ), and chip conveyor.

The tools used in the experiments are 4 flutes, $10 \mathrm{~mm}$ diameter titanium-coated carbide with flat end mill, and ball-nose end mill. These tools are characterized by high toughness and hardness due to the ultra-fine grade and TiAlN coating. The tool holder is split collet type, which is very popular on vertical milling machines. This type of split collet system is the collets chuck system where the tool slippage may be minimized. The workpiece material is S50C Medium Carbon Steel with carbon content between 0.3 and $0.8 \%$. The workpiece is a $60 \times 60 \times 60 \mathrm{~mm}$ square block. Table 3 shows the chemical composition of the work material in weight percent.

The end milling process was conducted in two stages using the proposed experimental setup and workpiece material. The first cutting stage entailed rough cutting to remove 


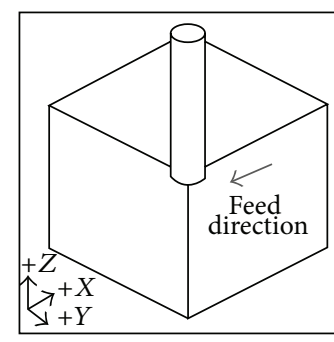

(a) Initial

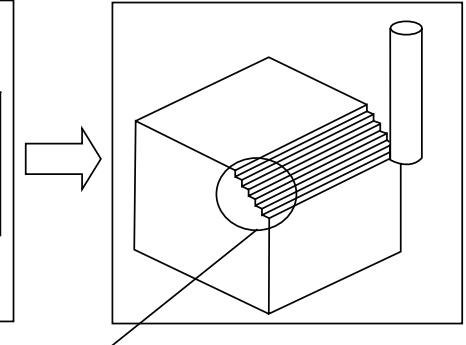

(b) Roughing

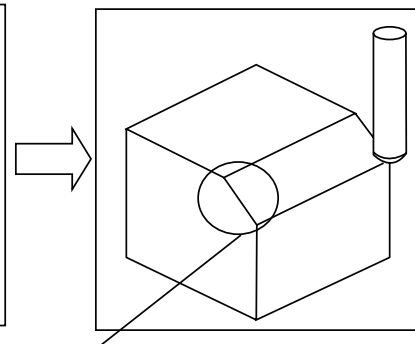

(c) Finishing
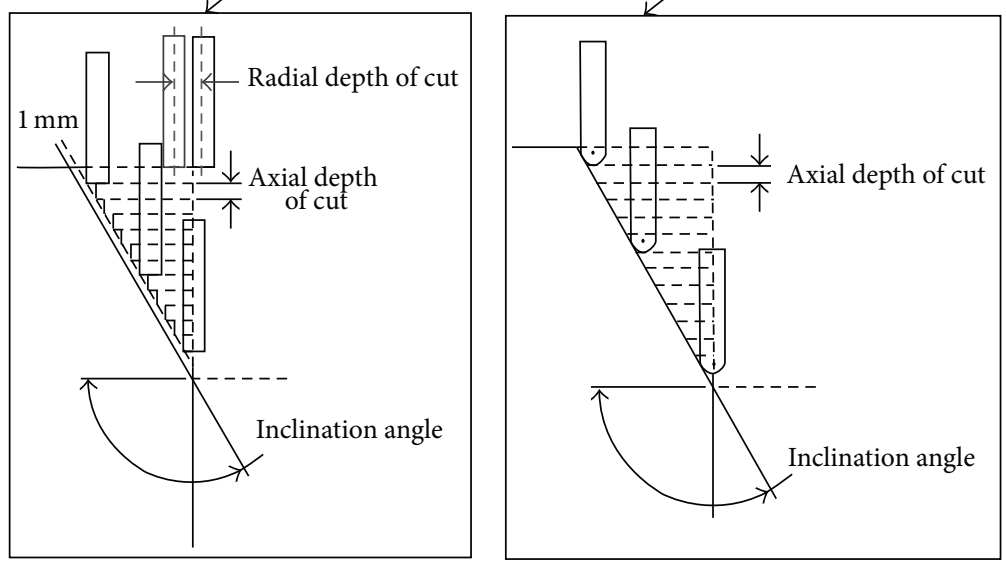

FIGURE 3: Machining processes.

TABLE 3: Chemical composition of medium carbon steel in weight percent.

\begin{tabular}{lcccc}
\hline $\mathrm{C}$ & $\mathrm{Si}$ & $\mathrm{Mn}$ & $\mathrm{P}$ & $\mathrm{S}$ \\
\hline $0.48-0.55$ & $0.15-0.35$ & $0.60-0.90$ & 0.04 & 0.05 \\
\hline
\end{tabular}

the excess material until the stairs step inclined plane was produced with different angles of 100, 110, and 120 degrees. A $10 \mathrm{~mm}$ diameter titanium-coated carbide flat end mill was used to prepare this cutting process. The cutting process started with the tool $Z$-axis coordinate initially sitting as shown in Figure 3(a) and was then moved in the $+X$ direction to cut a distance of $60 \mathrm{~mm}$ and in the $-Y$ direction with a step-over of $1 \mathrm{~mm}$ until it reached the machined surface inclination angle. At the end of the first cutting cycle the tool $Z$-axis coordinate had to be shifted to the assign axial depth of cut, to provide the feed motion while cutting in the $+X$ and $-Y$ directions was repeated to cut the same stroke. The same tool shifts and cutting cycle were applied to complete rough cutting to prepare the stairs step inclined plane, as shown in Figure 3(b).

The second cutting stage was finish cutting to produce a flat, smooth, inclined surface to investigate the influence of machined surface inclination angle on surface integrity in $2.5 \mathrm{D}$ cutting. In this cutting stage the end mill tool used was $10 \mathrm{~mm}$ diameter titanium-coated carbide ball-nose end mill. The tool moved in the $+X$ and $+Y$ directions to produce a flat, smooth, machined surface with different inclination angles, while the tool $Z$-axis coordinate was shifted at different axial depths of cut, as shown in Figure 3(c).
Lubrication was applied in order to control the temperature during cutting for better surface quality. The experimental test was conducted in flood condition. High pressure coolant in machining centers provides better cooling, increased tool life, reduced friction, and also improved machined surface finish. High pressure coolant removes chips from the machining area and reduces the issue with recutting chips.

To measure the machined surface microhardness, an HMV Microhardness Tester was used, with $1.961 \mathrm{~N}$ load, HV $=0.2$, and 10 seconds indentation time, while for microstructure and residual stress investigation the machined surface part was further cut into smaller size samples $(25 \times 25 \times$ $5 \mathrm{~mm}$ ) using a Sodick Electrical Discharge Wirecut Machine (EDM). The reason for choosing this machining process is that it produces very low heat-affected zone (HAZ) on the cutting surface so the machined surface will not be affected. Besides, its product is stress-free and burr-free. Each specimen was placed with carbon tape on a round platform to fit the location in the SEM. The microstructure of the machined surfaces was observed with a Philips Scanning Electron Microscope (SEM) XL40. It is considered one of the most versatile instruments available for examining microstructural characteristics and carrying out elemental analysis of solid objects at a magnification range of 10 to $400,000 \mathrm{x}$ and electron acceleration range of 0.2 to $30 \mathrm{kV}$. The SEM settings used were acceleration voltage of $10 \mathrm{kV}, 5.0$ spot, 1000x magnification, secondary detector, and 6.0 WD.

The residual stress on the machined surface inclination angle was measured using X-ray diffraction technique 
TABLE 4: XRD measurement parameters.

\begin{tabular}{lc}
\hline Measurement method & $\operatorname{Sin}^{2} \psi$ \\
Target & $\mathrm{Cu} \mathrm{K \alpha}$ \\
Tube voltage $(\mathrm{kV})$ & 45 \\
Tube current $(\mathrm{mA})$ & 30 \\
Peak $2 \theta\left(^{\circ}\right)$ & 116.5 \\
Start angle $\left(^{\circ}\right)$ & 113.5457 \\
Stop angle $\left(^{\circ}\right)$ & 119.4457 \\
$\Psi\left(^{\circ}\right)$ & $0,12.9,18.4,22.8,26.6,30.0,33.2$ \\
$\operatorname{Sin}^{2} \psi$ & $0,0.05,0.10,0.15,0.20,0.25,0.30$ \\
$\Phi\left(^{\circ}\right)$ & 0,90 \\
\hline
\end{tabular}

(XRD). Diffraction occurs at an angle of $2 \theta$, defined by Bragg's Law as $n \lambda=2 d \sin \theta$, where $n$ is an integer denoting the order of diffraction, $\lambda$ is the X-ray wavelength, $d$ is the lattice spacing of crystal planes, and $\theta$ is the diffraction angle. The strain in the crystal lattice is measured and the residual stress producing the strain is calculated. The presence of a tensile stress in the sample results in Poisson's ratio contraction, reducing the lattice spacing and slightly increasing the diffraction angle, $2 \theta$. If the sample is then rotated through some known angle $\psi$, the tensile stress present in the surface increases the lattice spacing over the stress-free state and decreases $2 \theta$. Measuring the change in angular position of the diffraction peak for at least two orientations of the sample defined by angle $\psi$ enables the calculation of the stress present in the sample surface lying in the plane of diffraction, which contains the incident and diffracted X-ray beam [24]. In this research, the stresses were measured parallel and perpendicular to the feed direction. The residual stress measurement parameters are listed in Table 4.

The most common method to determine stress is $\sin ^{2} \psi$. A number of XRD measurements are made at different angles $\psi$. By resolving the angular peak shift and applying Bragg's law to quantify the $d$-spacing, residual stress on the machined surface can be calculated using the theory of linear elasticity. The interplanar spacing, $d$, is measured and plotted versus $\sin ^{2} \psi$. The stress can then be calculated from such a plot by calculating the gradient of the line and with basic knowledge of the elastic properties of the material. By finding $m$, the gradient of the $d$ versus $\sin ^{2} \psi$ curve, the stress can be calculated using

$$
\sigma_{\emptyset}=\left(\frac{E}{1+v}\right) m .
$$

This formula is derived from Fitzpatrick et al. [25].

\section{Experimental Results and Analysis}

3.1. Experimental Results. The finish cutting process is carried out using a ball-nose end mill to produce a flat, smooth, inclined surface to investigate the influence of machined surface inclination angle on the surface integrity in $2.5 \mathrm{D}$ cutting. The calculated TPM and $S / N$ ratio for microhardness and residual stress are shown in Table 5 . The $S / N$ ratios transform several repetitions into one value which indicates the amount of variation present and the shift of mean response in order to identify the control factors that may reduce variation and improve quality. The method for calculating the $S / N$ ratio depends on the characteristic type, whether smaller is better, larger is better, or nominal is better. In the case of microhardness, larger values are preferred; meanwhile, for residual stresses smaller values are preferred, as they indicate compressive residual stress. Compressive residual stresses are always shown as negative values and tensile residual stresses are always shown as positive values. The equations for calculating the $S / N$ ratio with larger is better and smaller is better are as follows:

larger is better

$$
S / N_{i}=-10 \log \left(\frac{1}{n} \sum_{j=1}^{n} \frac{1}{y_{j}^{2}}\right) ;
$$

smaller is better

$$
S / N_{i}=-10 \log \left(\frac{1}{n} \sum_{j=1}^{n} y_{j}^{2}\right),
$$

where $y_{i}$ is the individual measured microhardness or residual stress and $n$ is the number of repetitions. The degree of predictable performance of a process in the presence of noise factors could be defined from $S / N$ ratios, whereby for each factor, the higher the $S / N$ ratio the better the result. Alternatively, target performance measurement (TPM) can also be used to analyze the quality. TPM is the average of the measured microhardness and residual stress at the same level of input parameters $(i)$.

The SEM micrographs of the surfaces generated for all nine experiments are shown in Figure 4. The micrographs indicate surface damage such as feed mark deformation, surface tearing, chip layer formation, micropits, redeposited work material (chips) onto the machined surface, and flaws.

3.2. Data Analysis. The next step in the Taguchi optimization method is to analyze the data, optimize the cutting parameters, and identify which process parameters are statistically significant. Data analysis is conducted using signal-to-noise $(S / N)$ and target performance measurement (TPM) response analysis and analysis of variance (Pareto ANOVA).

3.2.1. $S / N$ and TPM Response Analysis. The TPM and $S / N$ response data are calculated and summarized in Tables 6, 7, and 8 . As an example of response calculation, $A_{i}$ is the average of all TPM or $S / N$ values corresponding to the same level of input parameters ( $i$ ) under $A$ in Table 5. In this case, $(i)$ is equal to 1,2 , or 3 . The difference under the $A_{i}$ column in Tables 6,7 , and 8 is equal to the maximum minus the minimum of the TPM or $S / N$ response values. Similarly, the TPM, $S / N$ response values, and differences are calculated for $B_{i}, C_{i}$, and $D_{i}$. The rank is given in order from the highest to the lowest difference values. The significance of each factor is 
TABLE 5: Results of calculated TPM and $S / N$ ratios for microhardness and residual stress.

\begin{tabular}{|c|c|c|c|c|c|c|c|c|c|c|}
\hline \multirow{3}{*}{ Ex. number } & \multicolumn{4}{|c|}{ Factors } & \multicolumn{2}{|c|}{ Microhardness } & \multicolumn{4}{|c|}{ Residual stress } \\
\hline & \multirow[b]{2}{*}{$A_{i}$} & \multirow[b]{2}{*}{$B_{i}$} & \multirow[b]{2}{*}{$C_{i}$} & \multirow[b]{2}{*}{$D_{i}$} & \multirow[b]{2}{*}{ TPM (HV) } & \multirow[b]{2}{*}{$S / N(\mathrm{~dB})$} & \multicolumn{2}{|c|}{ Feed direction } & \multicolumn{2}{|c|}{ Cutting direction } \\
\hline & & & & & & & TPM (MPa) & $S / N(\mathrm{~dB})$ & TPM (MPa) & $S / N(\mathrm{~dB})$ \\
\hline 1 & 1 & 1 & 1 & 1 & 264.67 & 48.4514 & -452.31 & -56.2273 & -355.38 & -56.1861 \\
\hline 2 & 1 & 2 & 2 & 2 & 245.00 & 47.7549 & -242.31 & -58.6666 & -484.62 & -54.2426 \\
\hline 3 & 1 & 3 & 3 & 3 & 240.00 & 47.6005 & -710.77 & -51.8041 & 274.62 & -62.1076 \\
\hline 4 & 2 & 1 & 2 & 3 & 287.33 & 49.1667 & -743.08 & -51.0514 & -129.23 & -58.7981 \\
\hline 5 & 2 & 2 & 3 & 1 & 246.33 & 47.8303 & 371.54 & -63.3554 & -306.92 & -56.8157 \\
\hline 6 & 2 & 3 & 1 & 2 & 244.67 & 47.7656 & -662.31 & -52.8233 & -80.77 & -59.2685 \\
\hline 7 & 3 & 1 & 3 & 2 & 286.33 & 49.1369 & 484.62 & -63.9985 & -355.38 & -56.1861 \\
\hline 8 & 3 & 2 & 1 & 3 & 257.67 & 48.2125 & 355.38 & -63.2595 & -306.92 & -56.8157 \\
\hline 9 & 3 & 3 & 2 & 1 & 240.00 & 47.5920 & 420.00 & -63.6369 & 436.15 & -63.1440 \\
\hline
\end{tabular}

TABLE 6: TPM and $S / N$ response data for microhardness.

\begin{tabular}{|c|c|c|c|c|c|c|c|c|}
\hline \multirow{2}{*}{ Level of input parameters $(i)$} & \multicolumn{4}{|c|}{ TPM response data (HV) } & \multicolumn{4}{|c|}{$S / N$ response data $(\mathrm{dB})$} \\
\hline & $A_{i}$ & $B_{i}$ & $C_{i}$ & $D_{i}$ & $A_{i}$ & $B_{i}$ & $C_{i}$ & $D_{i}$ \\
\hline Level $1(i=1)$ & 249.89 & 279.44 & 255.67 & 250.33 & 143.81 & 146.75 & 144.43 & 143.87 \\
\hline Level $2(i=2)$ & 259.44 & 249.67 & 257.44 & 258.67 & 144.76 & 143.80 & 144.51 & 144.66 \\
\hline Level $3(i=3)$ & 261.33 & 241.56 & 257.56 & 261.67 & 144.94 & 142.96 & 144.57 & 144.98 \\
\hline Difference & 11.44 & 37.89 & 1.89 & 11.33 & 1.13 & 3.80 & 0.14 & 1.11 \\
\hline Rank & 2 & 1 & 4 & 3 & 2 & 1 & 4 & 3 \\
\hline
\end{tabular}

TABLE 7: TPM and $S / N$ response data for residual stress (feed direction).

\begin{tabular}{|c|c|c|c|c|c|c|c|c|}
\hline \multirow{2}{*}{ Level of input parameters $(i)$} & \multicolumn{4}{|c|}{ TPM response data (HV) } & \multicolumn{4}{|c|}{$S / N$ response data $(\mathrm{dB})$} \\
\hline & $A_{i}$ & $B_{i}$ & $C_{i}$ & $D_{i}$ & $A_{i}$ & $B_{i}$ & $C_{i}$ & $D_{i}$ \\
\hline Level $1(i=1)$ & -468.46 & -236.92 & -253.08 & 113.08 & -166.7 & -171.28 & -172.31 & -183.22 \\
\hline Level $2(i=2)$ & -344.62 & 161.54 & -188.46 & -140.00 & -167.23 & -185.28 & -173.35 & -175.49 \\
\hline Level $3(i=3)$ & 420.00 & -317.69 & 48.46 & -366.16 & -190.89 & -168.26 & -179.16 & -166.12 \\
\hline Difference & 888.46 & 479.23 & 301.54 & 479.24 & 24.19 & 17.02 & 6.85 & 17.1 \\
\hline Rank & 1 & 3 & 4 & 2 & 1 & 3 & 4 & 2 \\
\hline
\end{tabular}

TABLE 8: TPM and $S / N$ response data for residual stress (cutting direction).

\begin{tabular}{|c|c|c|c|c|c|c|c|c|}
\hline \multirow{2}{*}{ Level of input parameters $(i)$} & \multicolumn{4}{|c|}{ TPM response data (HV) } & \multicolumn{4}{|c|}{$S / N$ response data $(\mathrm{dB})$} \\
\hline & $A_{i}$ & $B_{i}$ & $C_{i}$ & $D_{i}$ & $A_{i}$ & $B_{i}$ & $C_{i}$ & $D_{i}$ \\
\hline Level $1(i=1)$ & -188.46 & -280.00 & -247.69 & -75.38 & -172.54 & -171.17 & -172.27 & -176.15 \\
\hline Level $2(i=2)$ & -172.31 & -366.15 & -59.23 & -306.92 & -174.88 & -167.87 & -176.18 & -169.70 \\
\hline Level $3(i=3)$ & -75.38 & 210.00 & -129.23 & -53.84 & -176.15 & -184.52 & -175.11 & -177.72 \\
\hline Difference & 113.08 & 576.15 & 188.46 & 253.08 & 3.6 & 16.65 & 3.91 & 8.02 \\
\hline Rank & 4 & 1 & 3 & 2 & 4 & 1 & 3 & 2 \\
\hline
\end{tabular}

determined based on the value of the difference of both $S / N$ and TPM.

For TPM, the desired larger-is-better criterion implies that the highest microhardness would be ideal and the smaller-is-better criterion implies that the lowest residual stress would be the ideal result, while the largest $S / N$ response would reflect the best response which results in the lowest noise for both. These are the criteria employed in this study to determine the optimal machining parameters.
The $S / N$ and TPM response graphs for selecting the best combination levels for maximum microhardness are shown in Figure 5. Based on the criteria of higher TPM and higher $S / N$ ratio, the axial depth of cut (Factor $B$ ) is found to be the most significant factor affecting microhardness, followed by machined surface inclination angle (Factor $A$ ), feed rate (Factor $D$ ), and spindle speed (Factor $C$ ) as shown in Table 6. The highest machined surface inclination angle $\left(A 3,120^{\circ}\right)$, with, lower axial depth of cut $(B 1,0.1 \mathrm{~mm})$, 


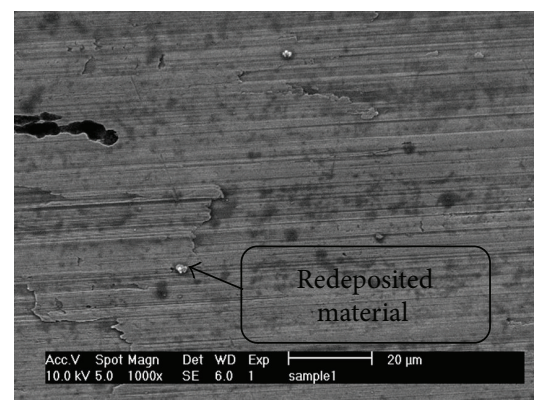

(a) Experiment 1

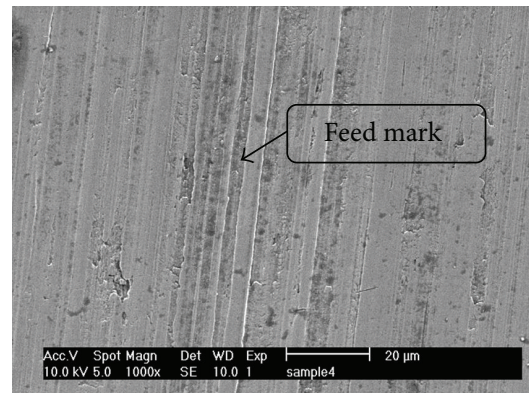

(d) Experiment 4

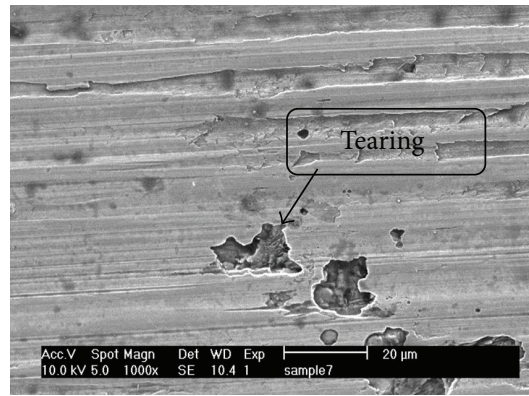

(g) Experiment 7

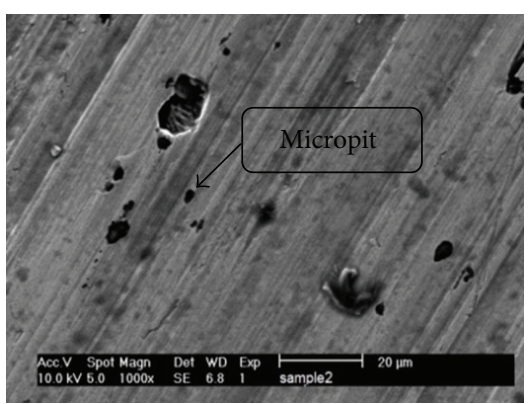

(b) Experiment 2

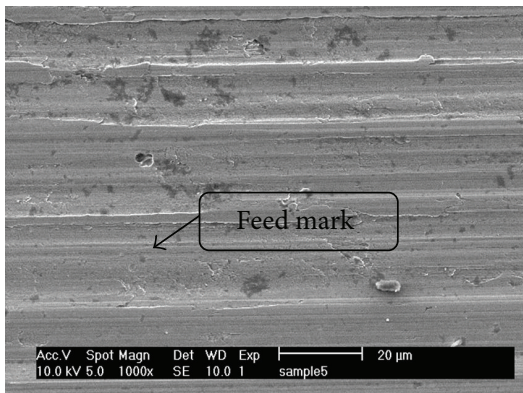

(e) Experiment 5

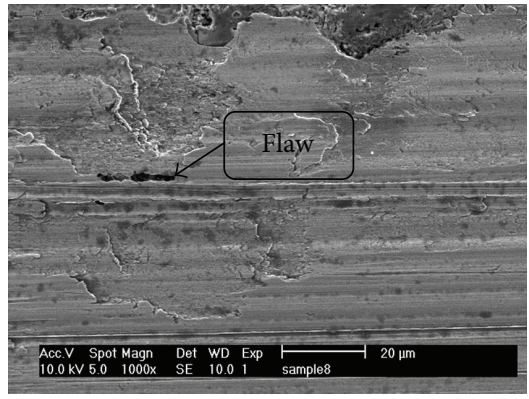

(h) Experiment 8

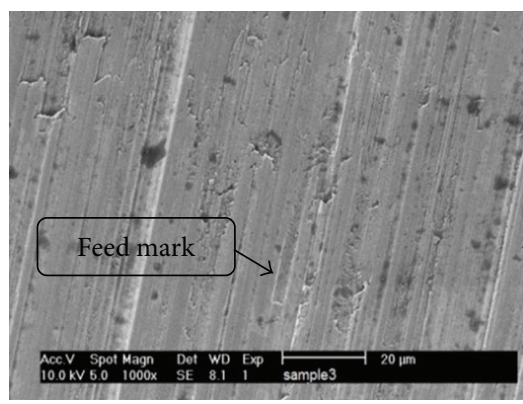

(c) Experiment 3

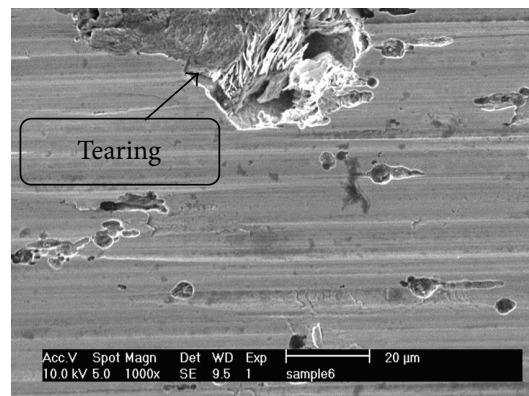

(f) Experiment 6

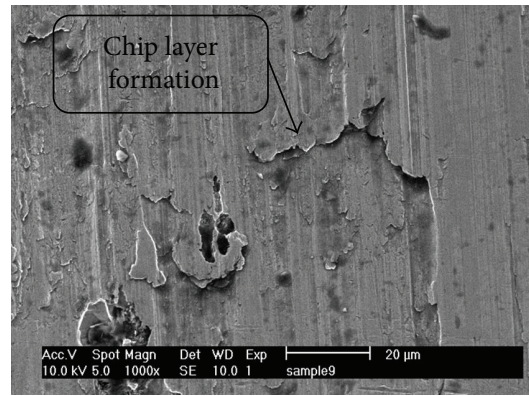

(i) Experiment 9

FIGURE 4: SEM micrographs of machined surfaces at 1000x.

higher spindle speed $\left(C 3,4200 \mathrm{~min}^{-1}\right)$, and higher feed rate $\left(D 3,970 \mathrm{~mm} \mathrm{~min}^{-1}\right)$ are determined as the best choices for obtaining the highest microhardness value. Therefore, the optimal parameters are set as $A 3 B 1 C 3 D 3$.

The $S / N$ and TPM response graphs for selecting the best combination levels for minimum residual stress in the feed direction are shown in Figure 6. According to the criteria of lower TPM and higher $S / N$ ratio, the machined surface inclination angle (Factor $A$ ) is found to be the most significant factor affecting residual stress in the feed direction, followed by feed rate (Factor $D$ ), axial depth of cut (Factor $B$ ), and spindle speed (Factor $C$ ), as shown in Table 7. The lowest machined surface inclination angle $\left(A 1,100^{\circ}\right)$ with higher axial depth of cut $(B 3,0.5 \mathrm{~mm})$, lower spindle speed $(C 1$, $\left.3200 \mathrm{~min}^{-1}\right)$, and higher feed rate $\left(D 3,970 \mathrm{~mm} \mathrm{~min}^{-1}\right)$ are determined to be the best choices for obtaining the lowest value of residual stress in the feed direction. Therefore, the optimal parameters are set as A1 B3 C1 D3.

The $S / N$ and TPM response graphs for selecting the best combination levels for minimum residual stress in the cutting direction are shown in Figure 7. Based on the criteria of lower TPM and higher $S / N$ ratio, the axial depth of cut (Factor $B$ ) is found to be the most significant factor affecting residual stress in the cutting direction, followed by feed rate (Factor $D$ ), spindle speed (Factor $C$ ), and machined surface inclination angle (Factor $A$ ), as shown in Table 8 . The lowest machined surface inclination angle $\left(A 1,100^{\circ}\right)$ and moderate axial depth of cut $(B 2,0.25 \mathrm{~mm})$, lower spindle speed $(C 1$, $\left.3200 \mathrm{~min}^{-1}\right)$, and moderate feed rate $\left(D 2,920 \mathrm{~mm} \mathrm{~min}^{-1}\right.$ ) are determined to be the best choices for obtaining the lowest value of residual stress in the cutting direction. Therefore, the optimal parameters are set as $A 1 B 2 C 1 D 2$.

3.2.2. Pareto ANOVA. Pareto ANOVA is a fast and simple way to analyze data for process optimization. This method enables the significance of factors and interactions to be evaluated through Pareto-type analysis. It also facilitates obtaining the optimal factor levels. Tables 9, 10, and 11 show the Pareto ANOVA for microhardness and residual stress in the feed and cutting directions, respectively, using the $S / N$ 


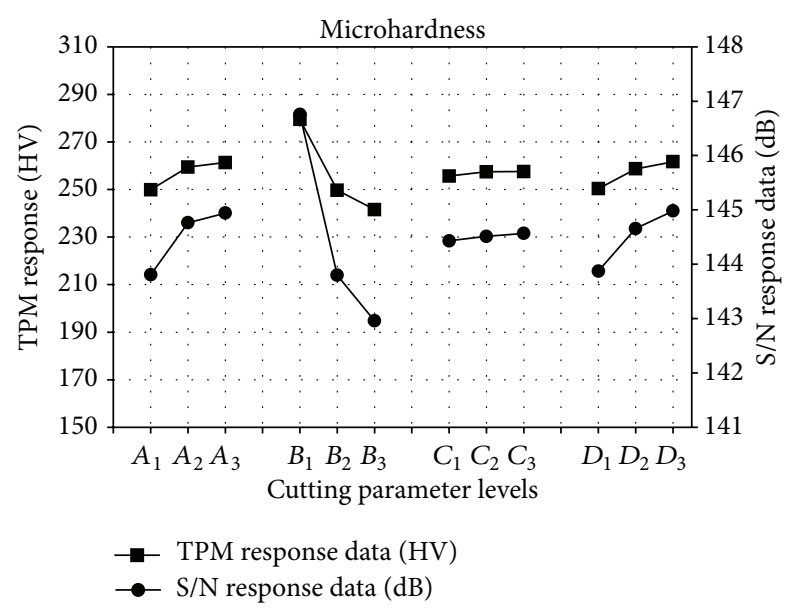

FIgURE 5: TPM and $S / N$ response graph for microhardness.

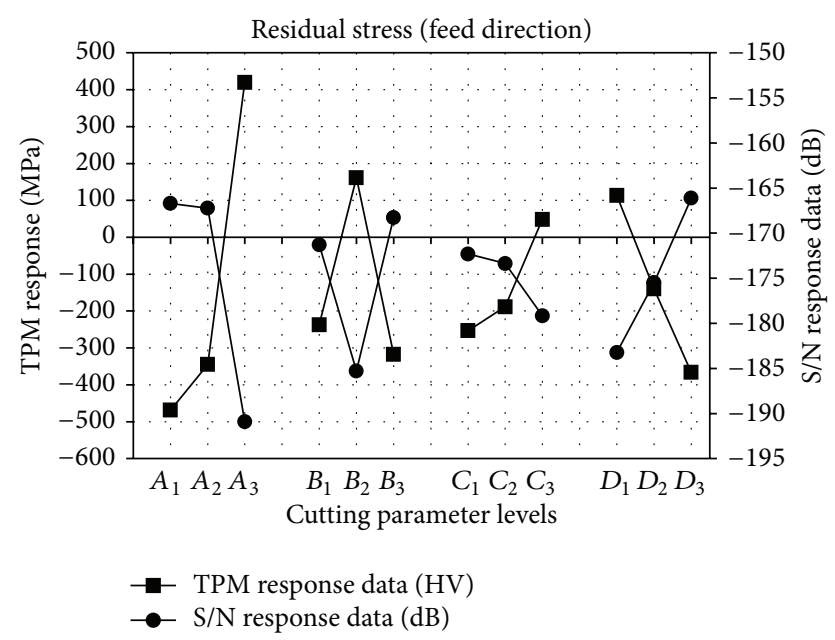

FIGURE 6: TPM and $S / N$ response graph for residual stress (feed direction).

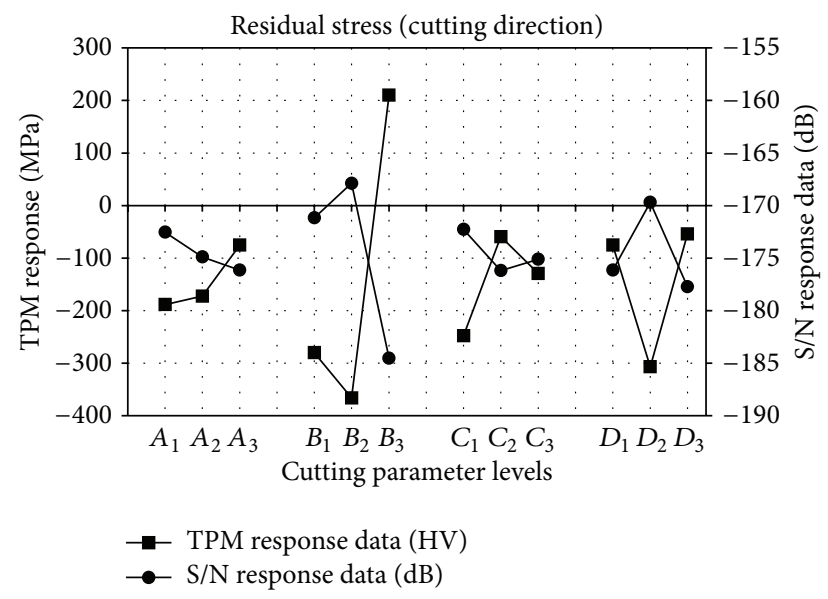

FIGURE 7: TPM and $S / N$ response graph for residual stress (cutting direction). response data from Table 5. The summation of squares of differences $(S)$ for each control factor is calculated such that, for example, $S_{A}$ can be obtained with the following equation:

$$
S_{A}=\left(A_{1}-A_{2}\right)^{2}+\left(A_{1}-A_{3}\right)^{2}+\left(A_{2}-A_{3}\right)^{2} \text {. }
$$

Similarly, $S_{B}, S_{C}$, and $S_{D}$ are calculated. The contribution ratio for each factor is calculated as the percentage of summation of squares of differences for each factor to the total summation of the squares of differences. A Pareto diagram is plotted using the contribution ratio and cumulative contribution.

The best factor combination levels for maximum microhardness, as shown in Table 9, are found as the axial depth of cut $(B) 85.0 \%$, machined surface inclination angle $(A)$ $8.0 \%$, feed rate $(D) 6.9 \%$, and spindle speed $(C) 0.1 \%$. The best factor combination levels for minimum residual stress in the feed direction, as shown in Table 10, are found as the machined surface inclination angle $(A) 53.0 \%$, axial depth of cut $(B) 22.9 \%$, feed rate $(D) 20.4 \%$, and, finally, spindle speed (C) $3.8 \%$. The best factor combination levels for minimum residual stress in the cutting direction, as shown in Table 11, are found as the axial depth of cut $(B) 75.3 \%$, feed rate $(D)$ $17.5 \%$, spindle speed $(C) 4.0 \%$, and machined surface inclination angle $(A) 3.3 \%$. The Pareto ANOVA analysis essentially helped determine that $A 3 B 1 C 3 D 3$ is the best combination of parameters to adhere to the highest microhardness value; $A 1 B 3 C 1 D 3$ is best for the lowest value of residual stress in the feed direction; and $A 1 B 2 C 1 D 2$ is best for the lowest value of residual stress in the cutting direction. These three best combination parameters are also similar to the optimum results obtained from the $S / N$ and TPM response analysis.

\section{Discussion}

Result analysis was done using signal-to-noise $(S / N)$, target performance measurement (TPM) response analysis and Pareto ANOVA. All techniques delivered similar results. Axial depth of cut (Factor $B$ ) was found to be the most significant factor affecting microhardness with contribution of $85.0 \%$, followed by machined surface inclination angle (Factor A), feed rate (Factor D), and spindle speed (Factor C) (Figure 5). A lower axial depth of cut demonstrated an increase in microhardness. By further decreasing axial depth of cut, the number of cutting paths increased, as seen in Figure 8 . The machined surface thermally induced at every cutting path and by increasing the number of cutting paths, rapid workpiece heating occurred, resulting in increased hardening. As the machined surface inclination angle increased, the contact area between the tool and machined surface increased, causing more material to be removed during machining, D2 > D1, as shown in Figure 9. In combination with higher speed and feed rate the heat generated during machining increased, hence increasing the temperature and plastic flow, resulting in greater hardening. A competing process between work hardening and thermal softening took place that affected the fundamental behavior of the workpiece material [20]. The instability in the form of plastic deformation due to high temperature in high speed machining led to softening of the machined surfaces [12]. 


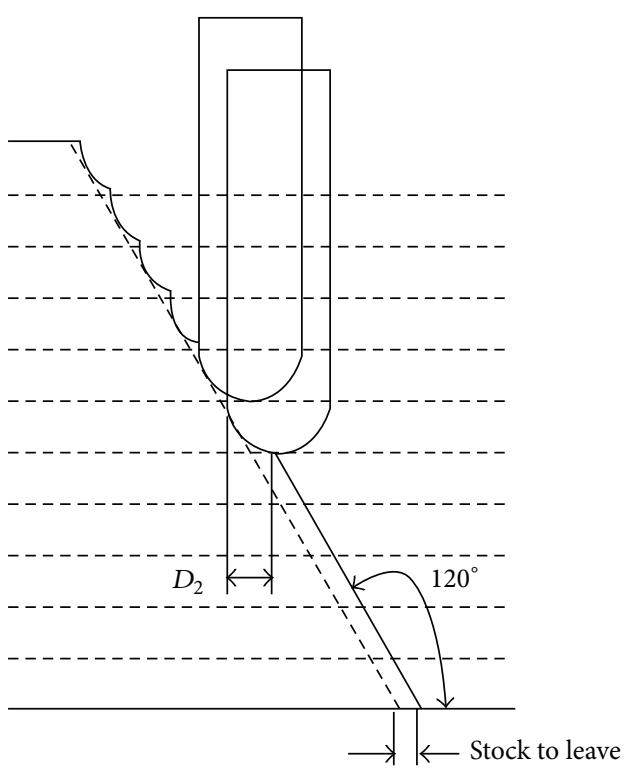

(a) Higher axial depth of cut

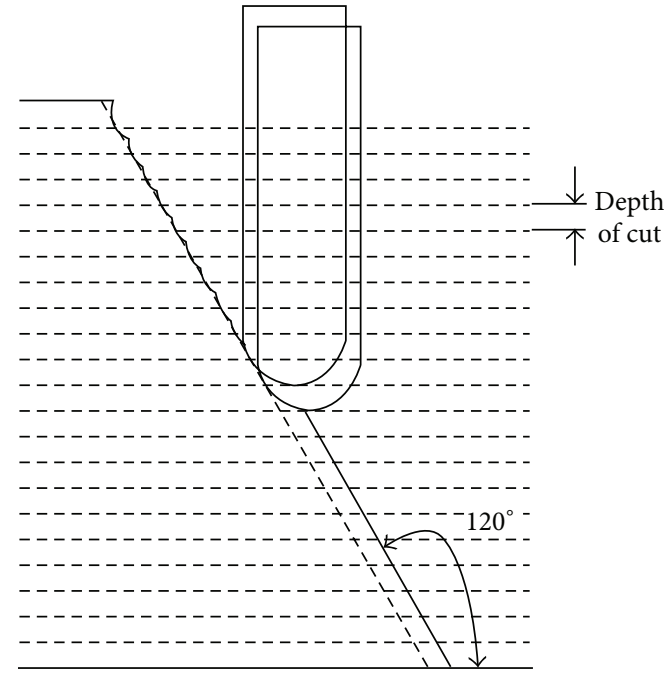

(b) Lower axial depth of cut

FIgURE 8: Machining processes with different axial depths of cut.

TABLE 9: Pareto ANOVA analysis for microhardness.

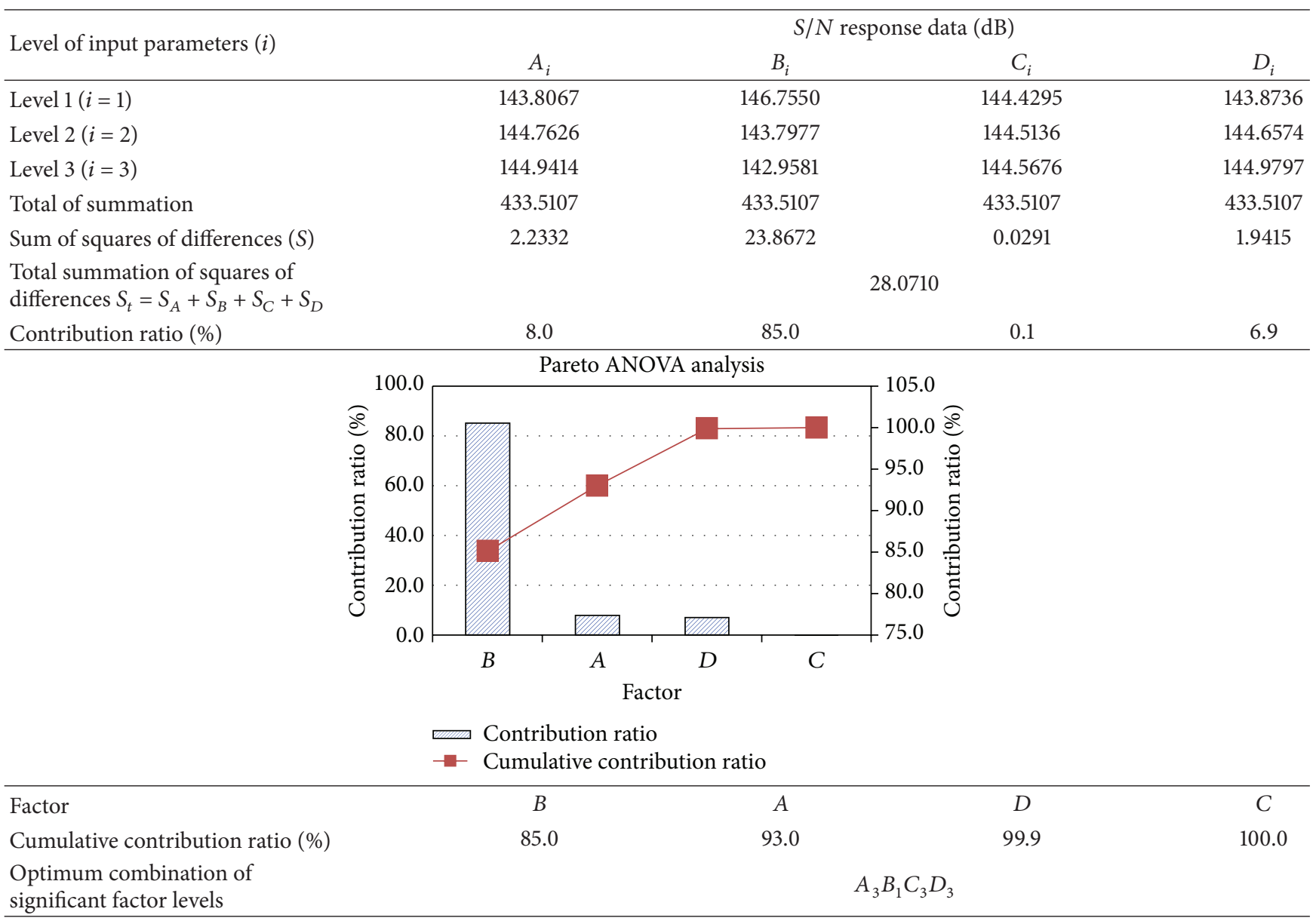


TAble 10: Pareto ANOVA analysis for residual stress (feed direction).

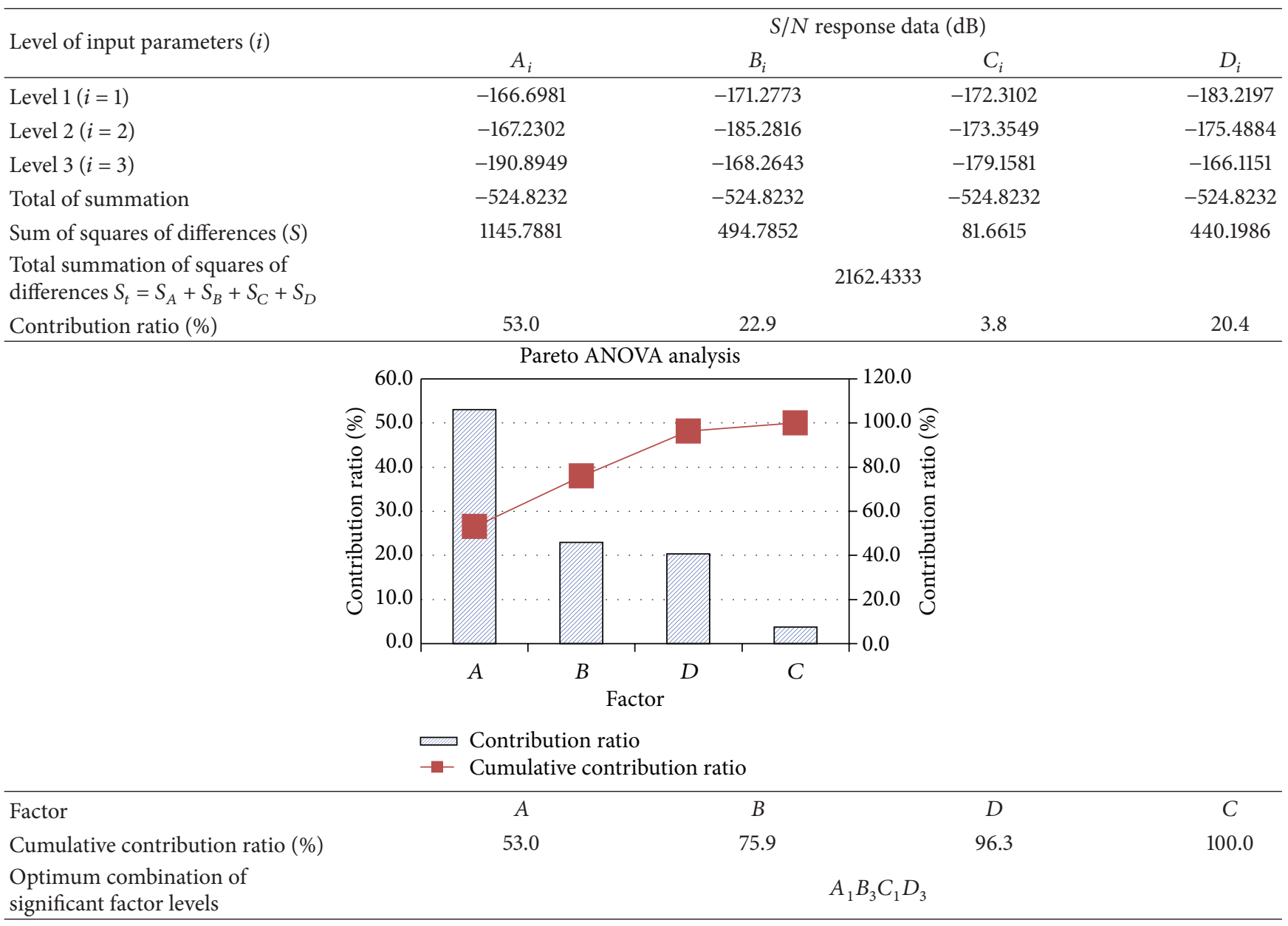

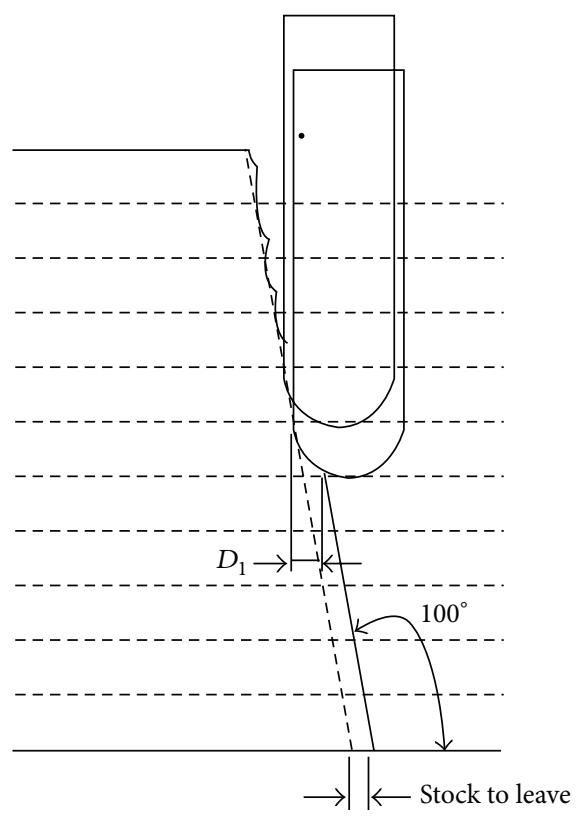

(a) Lower machined surface inclination angle

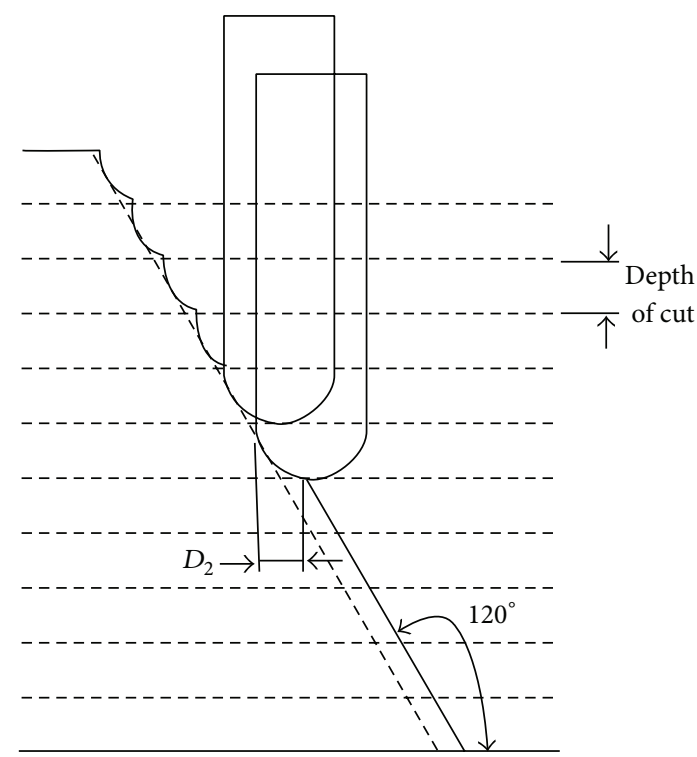

(b) Higher machined surface inclination angle

FIGURE 9: Machining processes with different machined surface inclination angles. 
TABle 11: Pareto ANOVA analysis for residual stress (cutting direction).

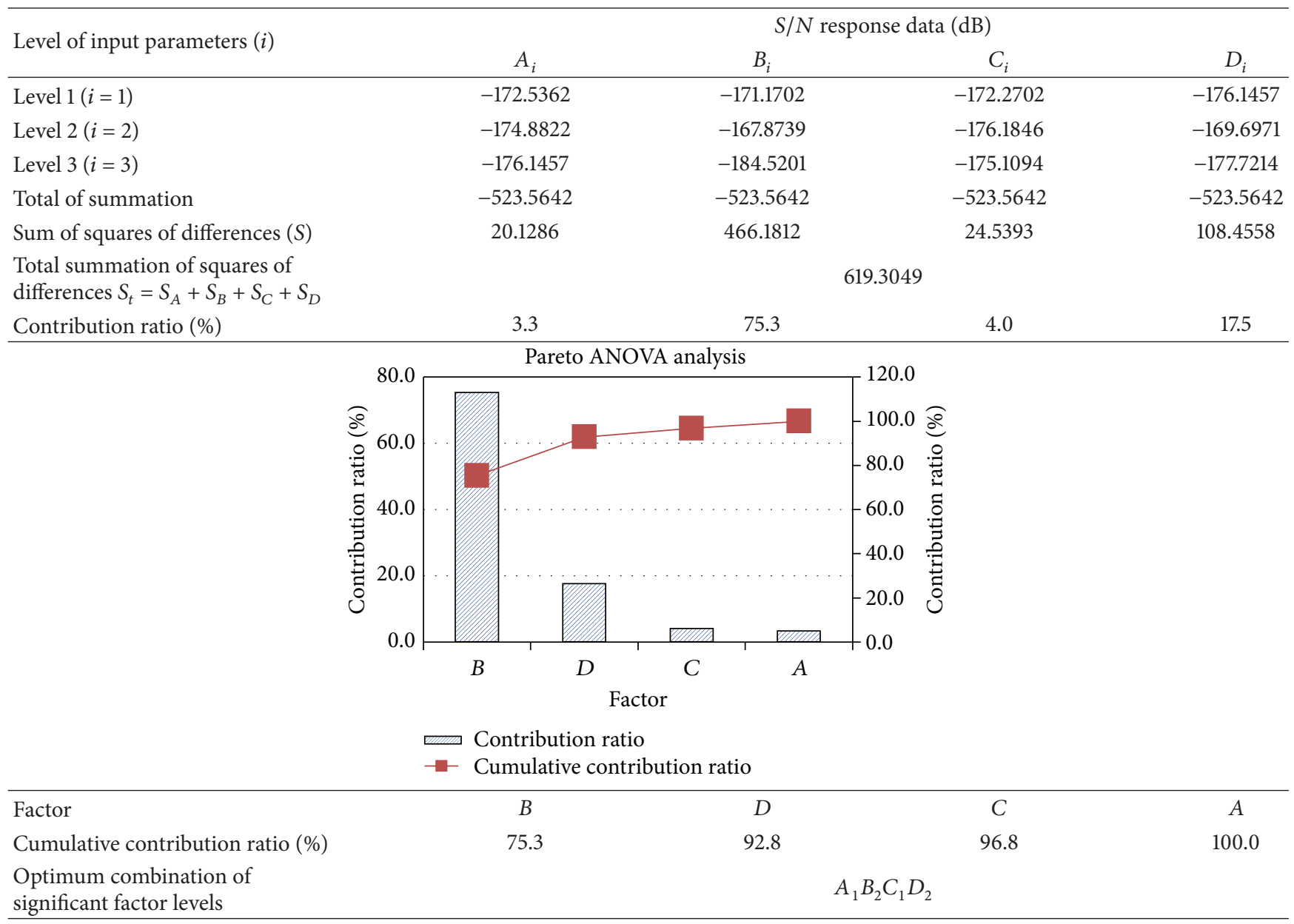

Sufficient coolant between the tool and machined surface caused the softened machined surface to harden due to the subsequent rapid cooling. Increasing the machined surface inclination angle allowed the access of more coolant to the tool-machined surface interface (Figure 9). Meanwhile, as the feed rate increased, the depth of the affected layer increased [18]. Furthermore, the greater hardening as feed rate increased owing to the increase in cutting temperatures which led to thermal deformation in the matrix material could be one reason behind the hardening of the machined surface. In addition, there was an increase in both chip thickness and tool chip contact length, which increased the cutting temperature and cutting force as the feed and speed increased [11].

During the cutting process, the heat produced expands the machined surface layer and produces compressive residual stress. However, when the workpiece is cooled, the machined surface layer should contract more, which is not permitted by the lower layer, thus producing tensile residual stress [26]. This is what happens during cutting with high machined surface inclination angle where the surrounding area between the tool and machined surface interface (Figure 9) is larger, allowing for more coolant to access the interface, hence inducing contraction.
In the cutting direction, moderate axial depth of cut produced compressive residual stress; however, as the axial depth of cut increased the residual stress became tensile due to the increased work hardening and rising temperature. Increasing the cutting speed increased the heat generated on the machined surface, which decreased the level of compressive residual stresses. At lower machined surface inclination angle, a higher feed rate produced compressive stress due to the steep residual stress. Variations in residual stress occurred, which were affected by the measurement sources, such as method of curve fitting to test data, measurement repeatability, and various sources of uncertainty [12]. On the machined surface, variation between replicated data was 15$20 \%$, probably due to the relatively high surface roughness which scattered the X-ray beam; below the machined surface where the surface roughness was lower owing to the electrochemical machining used to remove the surface layer, the variation between the replicated readings ranged from 6 to $15 \%$ [17]. Moreover, the increased cutting temperature caused plastic flow of material during machining to occur, which created deformation of feed marks on the machined surface and hence produced a rougher surface [19] as shown in the SEM micrographs especially for experiments 3 and 4, Figures 4(c), 4(d), and 4(e). Well-defined, uniform feed 
marks as well as grooves were found on the machined surface. The reason behind the groove formation is that the workpiece material particles were pulled out and got dragged over the machined surface, causing scratches and increasing the surface roughness [27]. Besides, micropits were also found on the surfaces due to brittle fractures of hard carbide inclusion within the immediate surface during workpiece material shearing by the tool (Figures 4(a) and 4(b)). Furthermore, surface tearing was randomly observed on the machined samples [20]. Surface tearing is likely to occur on account of the cutting tool part (small part that peels off from its origin to form tool wear) and built-up edge (BUE) deposited on the machined surface (Figures 4(f) and 4(g)).

\section{Confirmation Test}

After the optimal levels of all control factors were identified, a confirmation test was conducted using the optimal parameters to validate the findings. The microhardness obtained from the confirmation test is $289.33 \mathrm{HV}$, which is very close to the highest microhardness value in Table 5. The result indicates an improvement of only $0.7 \%$ in the microhardness obtained during the experiments. The residual stress in the feed direction obtained from the confirmation test is $-912.316 \mathrm{MPa}$, which is an improvement of $18.6 \%$ from the lowest result obtained during the experiments. Meanwhile, the residual stress in the cutting direction obtained from the confirmation test is $-573.08 \mathrm{MPa}$, signifying an improvement of $15.4 \%$ from the lowest result obtained during the experiments.

\section{Conclusions}

The focus of this research was to optimize the cutting parameters used in $2.5 \mathrm{D}$ end milling cutting in order to obtain better surface integrity in terms of microhardness and residual stress. Taguchi optimization was utilized to design the experimental work, while data analysis was conducted to find the optimum conditions using target performance measurement (TPM), signal-to-noise ratio $(S / N)$ response analysis, and analysis of variance (Pareto ANOVA). Through the analysis, it was found that machined surface inclination angle had great influence on microhardness and residual stress in the feed direction. As the machined surface inclination angle was increased, the microhardness also increased. However, residual stress showed the opposite results, whereby as the machined surface inclination angle increased the residual stress became more tensile. Axial depth of cut only had significant effect on residual stress in the cutting direction. Cutting speed seemed to have less influence on microhardness and residual stress, with a very low percentage of significant value. Meanwhile, feed rate had moderate influence on surface integrity. From the SEM micrographs it is observed that the major damage on the machined surface entailed feed mark deformation, surface tearing, chip layer formation, micropits, redeposited work material (chip) onto the machined surface, and flaws.

\section{Conflict of Interests}

The authors declare that there is no conflict of interests regarding the publication of this paper.

\section{Acknowledgments}

This research was supported by University of Malaya, Postgraduate Research Fund (PV066/2011B), and Universiti Kuala Lumpur, Institute of Product Design and Manufacturing. The authors would also like to thank Mr. Ahmad Fauzi for his assistance in the experimental work.

\section{References}

[1] A. Hatna, "Automatic CNC milling of pockets: geometric and technological issues," Computer Integrated Manufacturing Systems, vol. 11, no. 4, pp. 309-330, 1998.

[2] Y. Lee and T. Chang, "Application of computational geometry in optimizing $2.5 \mathrm{D}$ and $3 \mathrm{D}$ NC surface machining," Computers in Industry, vol. 26, no. 1, pp. 41-59, 1995.

[3] P. E. Romero, R. Dorado, F. A. Díaz, and E. M. Rubio, "Influence of pocket geometry and tool path strategy in pocketmilling of UNS A96063 alloy," Procedia Engineering, vol. 63, pp. 523-531, 2013.

[4] C. Gologlu and N. Sakarya, "The effects of cutter path strategies on surface roughness of pocket milling of 1.2738 steel based on Taguchi method," Journal of Materials Processing Technology, vol. 206, no. 1-3, pp. 7-15, 2008.

[5] S. K. Gupta, S. K. Saini, B. W. Spranklin, and Z. Yao, "Geometric algorithms for computing cutter engagement functions in $2.5 \mathrm{D}$ milling operations," Computer Aided Design, vol. 37, no. 14, pp. 1469-1480, 2005.

[6] D. Veeramani and Y. Gau, "Selection of an optimal set of cutting-tool sizes for $21 / 2 \mathrm{D}$ pocket machining," CAD Computer Aided Design, vol. 29, no. 12, pp. 869-877, 1997.

[7] A. Hamdan, A. A. D. Sarhan, and M. Hamdi, "An optimization method of the machining parameters in high-speed machining of stainless steel using coated carbide tool for best surface finish," The International Journal of Advanced Manufacturing Technology, vol. 58, no. 1-4, pp. 81-91, 2012.

[8] M. Sayuti, A. A. D. Sarhan, M. Fadzil, and M. Hamdi, "Enhancement and verification of a machined surface quality for glass milling operation using CBN grinding tool-Taguchi approach," International Journal of Advanced Manufacturing Technology, vol. 60, no. 9-12, pp. 939-950, 2012.

[9] R. Hood, D. K. Aspinwall, S. L. Soo, A. L. Mantle, and D. Novovic, "Workpiece surface integrity when slot milling $\gamma$-TiAl intermetallic alloy," CIRP Annals. Manufacturing Technology, vol. 63, pp. 53-56, 2014.

[10] K. Moussaoui, M. Mousseigne, J. Senatore, R. Chieragatti, and F. Monies, "Influence of milling on surface integrity of Ti6Al4Vstudy of the metallurgical characteristics: microstructure and microhardness," International Journal of Advanced Manufacturing Technology, vol. 67, no. 5-8, pp. 1477-1489, 2013.

[11] W. Li, Y. B. Guo, M. E. Barkey, and J. B. Jordon, "Effect tool wear during end milling on the surface integrity and fatigue life of Inconel 718," Procedia CIRP, vol. 14, pp. 546-551, 2014.

[12] J. Sun and Y. B. Guo, "A comprehensive experimental study on surface integrity by end milling Ti-6Al-4V," Journal of Materials Processing Technology, vol. 209, no. 8, pp. 4036-4042, 2009. 
[13] P. J. Withers and H. K. D. H. Bhadeshia, "Residual stress part 1-measurement techniques," Materials Science and Technology, vol. 17, no. 4, pp. 355-365, 2001.

[14] J. E. Wyatt and J. T. Berry, "A new technique for the determination of superficial residual stresses associated with machining and other manufacturing processes," Journal of Materials Processing Technology, vol. 171, no. 1, pp. 132-140, 2006.

[15] P. Chevrier, A. Tidu, B. Bolle, P. Cezard, and J. P. Tinnes, "Investigation of surface integrity in high speed end milling of a low alloyed steel," International Journal of Machine Tools and Manufacture, vol. 43, no. 11, pp. 1135-1142, 2003.

[16] A. Maurotto, D. Tsivoulas, and M. G. Burke, "Surface integrity in dry milling of 304L steel: a parametric study," Procedia CIRP, vol. 13, pp. 156-162, 2014.

[17] D. A. Axinte and R. C. Dewes, "Surface integrity of hot work tool steel after high speed milling-experimental data and empirical models," Journal of Materials Processing Technology, vol. 127, no. 3, pp. 325-335, 2002.

[18] N. Suresh Kumar Reddy, S. Kwang-Sup, and M. Yang, "Experimental study of surface integrity during end milling of $\mathrm{Al} / \mathrm{SiC}$ particulate metal-matrix composites," Journal of Materials Processing Technology, vol. 201, no. 1-3, pp. 574-579, 2008.

[19] E. O. Ezugwu, J. Bonney, R. B. da Silva, and O. Çakir, "Surface integrity of finished turned Ti-6Al-4V alloy with PCD tools using conventional and high pressure coolant supplies," International Journal of Machine Tools and Manufacture, vol. 47, no. 6, pp. 884-891, 2007.

[20] A. Ginting and M. Nouari, "Surface integrity of dry machined titanium alloys," International Journal of Machine Tools and Manufacture, vol. 49, no. 3-4, pp. 325-332, 2009.

[21] S. H. Park, Robust Design and Analysis for Quality Engineering, Chapman \& Hall, 1996.

[22] R. Sreenivasulu, "Optimization of surface roughness and delamination damage ofGFRP composite material in end milling using Taguchi designmethod and artificial neural network," Procedia Engineering, vol. 64, pp. 785-794, 2013.

[23] T. Kivak, "Optimization of surface roughness and flank wear using theTaguchi method in milling of Hadfield steel with PVD and CVDcoated inserts," Measurement, vol. 50, pp. 19-28, 2014.

[24] P. S. Prevéy, "Research, X-ray diffraction residual stress techniques," Metals Handbook, vol. 10, pp. 380-392, 1986.

[25] M. E. Fitzpatrick, A. T. Fry, P. Holdway, F. A. Kandil, J. Shackleton, and L. Suominen, "Determination of residual stresses by $\mathrm{X}$ ray diffraction. issue 2," Measurement Good Practice Guide, vol. 52, 2005.

[26] F. Gunnberg, M. Escursell, and M. Jacobson, “The influence of cutting parameters on residual stresses and surface topography during hard turning of $18 \mathrm{MnCr} 5$ case carburised steel," Journal of Materials Processing Technology, vol. 174, no. 1-3, pp. 82-90, 2006.

[27] M. El-Gallab and M. Sklad, "Machining of $\mathrm{Al} / \mathrm{SiC}$ particulate metal matrix composites. Part II. Workpiece surface integrity," Journal of Materials Processing Technology, vol. 83, no. 1-3, pp. 277-285, 1998. 

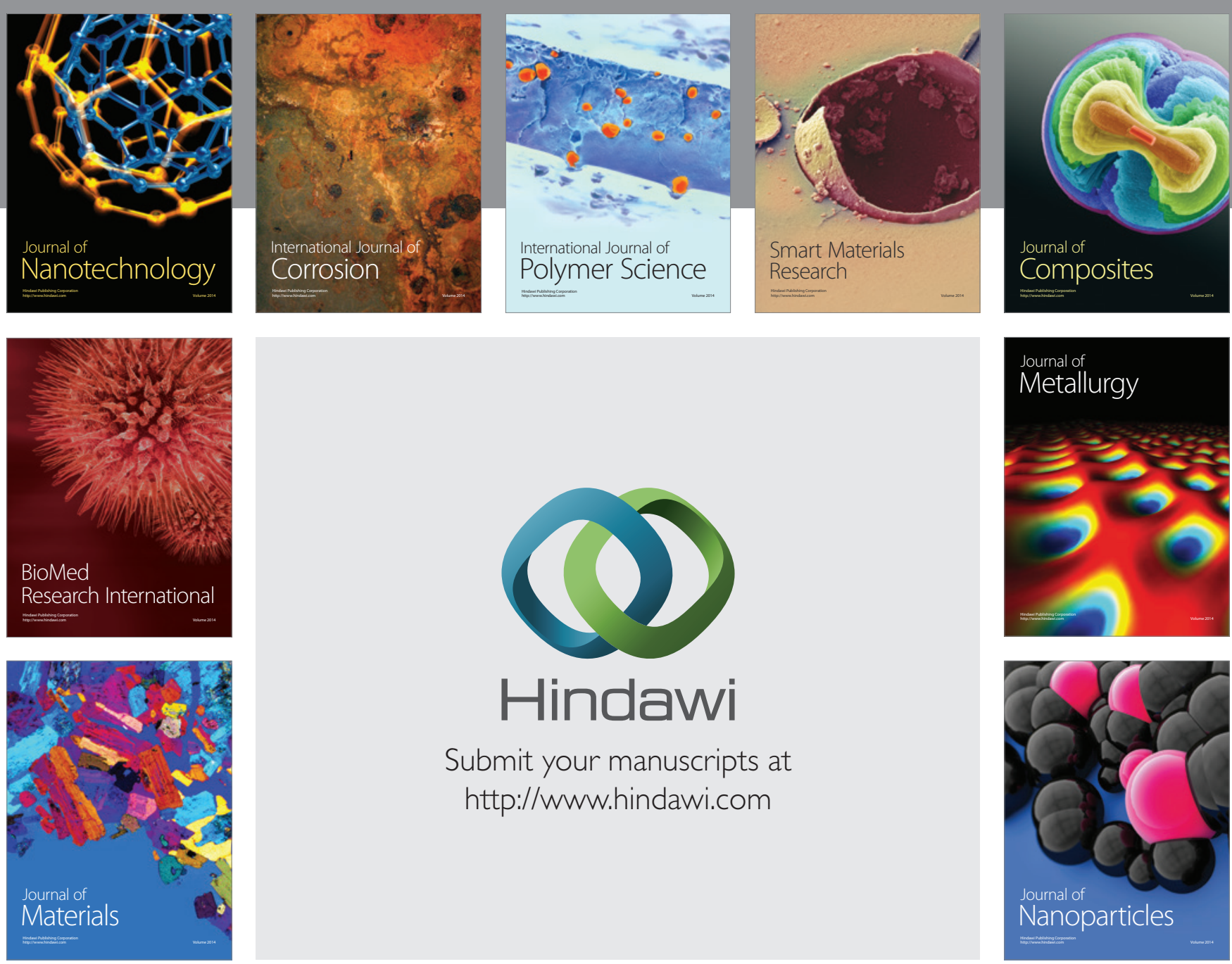

Submit your manuscripts at http://www.hindawi.com
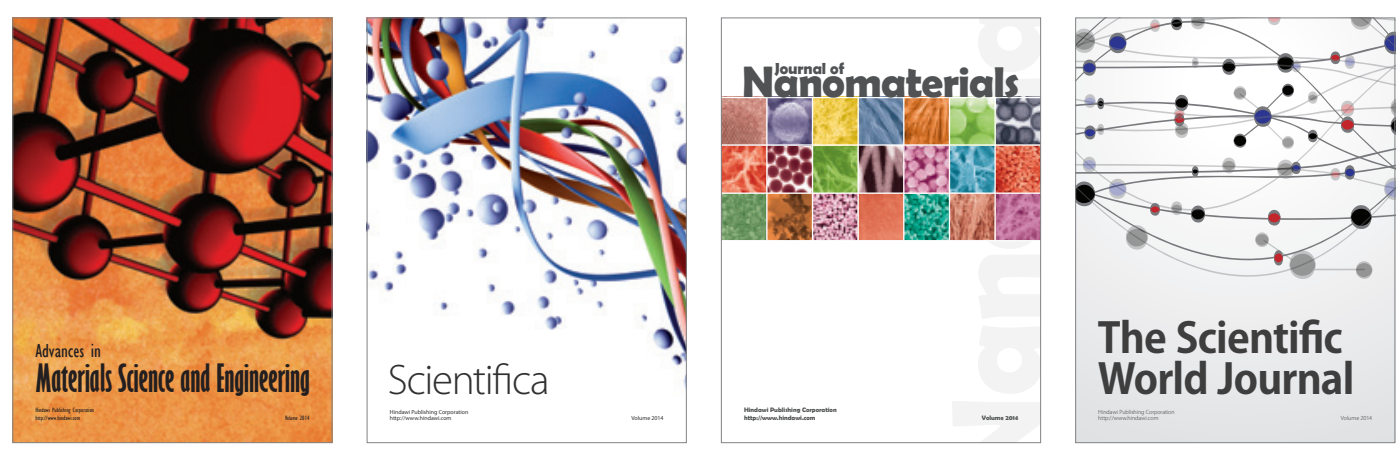

\section{The Scientific World Journal}
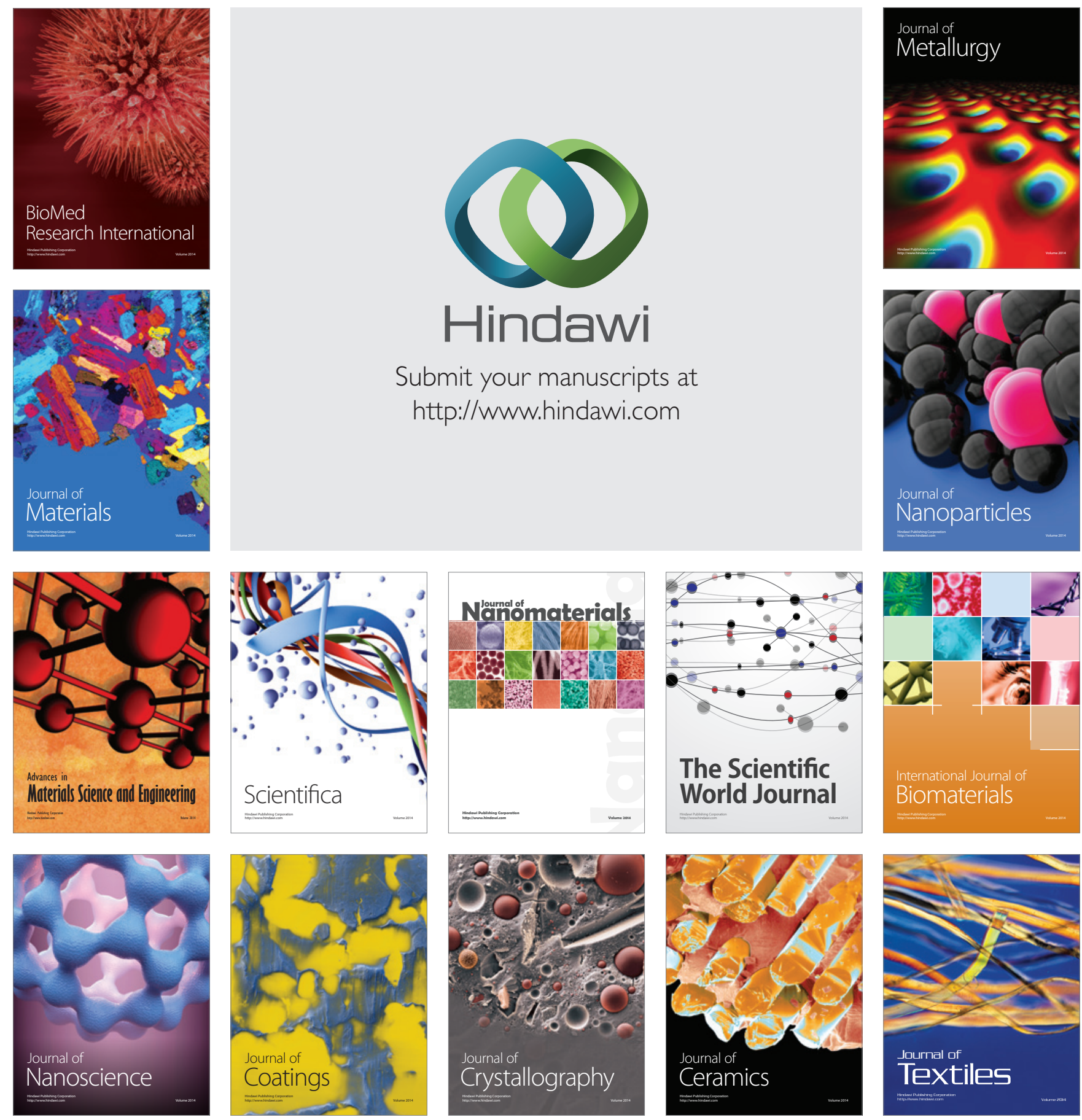